\title{
'n Nuwe psalmomdigting in Afrikaans: Uitgangspunte, beleid, probleme
}

\author{
Elsabé Kloppers \\ Direkteur: Instituut vir Kerkmusiek Suid-Afrika
}

\begin{abstract}
A new Metrical Psalter in Afrikaans: Premises, policy, problems For almost twenty years a commission of the Afrikaans-speaking Dutch Reformed churches has been working on a new metrical Psalter. The policy of versifying the Biblical texts is rigid and in many instances theologically outdated. The primary problems are the principle of a reproductive versification, a versification in one form and style, the lack of a hermeneutical approach, the question whether all 150 Psalms need to be reproduced anew and the lack of a proper liturgical function of many of the texts.
\end{abstract}

The business of a hymn is to strengthen the faith of today, and not to present a historical record of the faith the day before yesterday.

Bernard Manning

\section{PROBLEEMSTELLING}

Vir bykans twintig jaar reeds werk die interkerklike Psalmkommissie aan 'n nuwe omdigting van die psalms in Afrikaans. Riglyne waarvolgens gewerk word, is lank tevore reeds vasgestel. In die proses van werksaamheid oor die jare het hierdie beginsels in 'n groot mate verabsoluteer geraak. Baie vrae oor die omdigting word tans gevra, veral deur liturge wat die psalms vir liturgiese gebruik moet ontsluit. 'n Diepgaande teologiese gesprek is dringend noodsaaklik. Baie van die sake in hierdie bespreking is in noue aansluiting by wat ek reeds vroeër beredeneer het (vgl Kloppers 1994b:24-32; 1997:217243). 
Vrae oor die psalms wat herhaaldelik gehoor word, is die volgende:

- Word die nuwe psalms dinamies en in 'n meer eietydse taal en vorm omgedig?

- Word die tekste in singbare en sinvolle eenhede weergegee?

- Is die musiek "singbaar"?

- Is alle psalmomdigtings as liedere liturgies bruikbaar? Kan alle psalms, ook die wraakpsalms, kollektief deur Christene gesing word?

- Moet al 150 psalms opnuut in een bepaalde vorm omgedig word - selfs dié wat liturgies minder funksioneel is? Al 150 psalms is immers reeds in omgedigte vorm in Afrikaans beskikbaar.

- Word verskeidenheid van style en vorme gereflekteer, of is slegs 'n omvattende, lang strofiese vorm ter sprake wat nie veel van die huidige Totiusberyming verskil nie?

\section{VEREISTES VIR DIE TEKSTE VAN LIEDERE}

Die eerste vereiste wat aan die tekste van liedere gestel word, is dat dit in ooreenstemming met die Woord en die belydenis moet wees. Vanuit 'n hermeneutiese perspektief is dit duidelik dat die Bybelwoord nie woordeliks ná gesing kan word nie, tensy die letterlike tekens en simbole van die Bybelteks sélf gesing word, dus die oorspronklike taal van die oerteks (of wat ookal as die oerteks beskou kan word). Om egter te verstaan wat gesing word, moet die "oorspronklike" Bybelteks in vertaalde vorm gesing word. Enige vorm van vertaling is altyd rééds interpretasie. Die teks van 'n kerklied en die skeppingsproses kan met dié van die prediking vergelyk word (vgl Kloppers 1992/ 1994a). Soos die homileet, herhaal die digter nie bloot die Bybelteks nie, maar interpreteer dit en giet dit in 'n ander vorm - in nuwe, eietydse simbole en taal, sodat die eietydse hoorders/sangers dit kan verstaan. Die herskeppingsproses hou egter nie hier op nie. Wanneer dit in die mond van gelowiges geneem en gesing word, word daar ' $n$ bepaalde betekenis aan die lied toegeken (vgl die resepsieteorieë van Jauß e a 1969/1982).

Wat kom dus alles ter sprake wanneer 'n psalm omgedig word? In die eerste plek 'n bepaalde Bybelteks wat binne 'n bepaalde konteks ontstaan het en binne 'n bepaalde konteks gekanoniseer is. Die hele Universalgeschichte kom ter sprake. Wat het aanleiding gegee tot die ontstaan van die teks en wat word daardeur gekommunikeer? Wat 
was die teks se Sitz im Leben? Watter tradisies is reeds in die teks opgesluit? Watter faktore het 'n rol gespeel en watter belange is gedien by kanonisering? Watter struktuur en metaforiese taal vertoon die teks? Wat moet in berekening gebring word wanneer gepoog word om in 'n omdigting so ná as moontlik aan die oorspronklike te hou? Kan botsende teologieë in één liedteks opgeneem word? Verder moet gevra word na die verskeidenheid van moontlike interpretasies van die Bybelteks deur die huidige leser/eksegeet/lieddigter. Watter rol speel elkeen se eie verstaanshorison, (teologiese) agtergrond, belange wat gedien moet word? Tydens die omdigting moet die volgende egter ook in aanmerking geneem word: Vir wie en met watter doel word 'n teks omgedig? Watter betekenismoontlikhede kan deur die sanger aan die lied toegeken word? Watter misverstande kan by die sanger ontstaan? Watter rol speel die sanger se eie verstaanshorison en situasie? Watter faktore speel 'n rol by die resepsie van liedere?

\section{3. 'N REPRODUKTIEWE OMDIGTING VAN DIE PSALMS?}

'n Bepaalde Bybelteks moet vir elke tyd anders gesê word ten einde nuut gesê te word vergelyk Ricoeur (1987:238) wat aandui dat 'n (poëtiese) teks ons blik op die werklikheid nuut wil orden. Die psalms as lied, soos die preek of enige liturgiese lied, moet in omgedigte vorm die boodskap op 'n eksistensieel-relevante wyse vir die eietydse mens nuut verklank. Die wesenlike vraag is hoe die psalms in 'n "reproduktiewe omdigting" eietyds-relevant kan kommunikeer. 'n Reproduktiewe omdigting kom immers neer op 'n verabsolutering van die tekens en simbole waarin die teks gegiet is. Dit kom neer op dit wat by 'n preek nié, gedoen behoort te word nie - die blote nasê van die Bybelteks. 'n Reproduktiewe omdigting kan weliswaar as 'n vorm van "skriflesing" funksioneer, maar dit beteken dat so 'n psalm dikwels verduidelik en uitgelê moet word, dat dit in eietydse taal en simbole opnuut "vertaal" en dus opnuut geïnterpreteer moet word. Daar moet dus 'n gesproke kontekstueel-Christelike uitleg, daarby gegee word, wat beteken dat so 'n reproduktief-omgedigte teks nie sonder meer as lied outonoom in die mond en gedagtes van die gelowiges kan leef nie. Dit is 'n onhoudbare minagting van die wese en funksie van die kerklied.

'n Verdere vraag is dus hoe sodanige náseggings in die liturgie van 'n Christelike gemeente moet funksioneer? Wanneer 'n predikant uit of oor 'n psalm preek, sê hy of sy 
(in eie woorde) wat in die psalm staan. Dít wat die psalm vir vandag se Christene sê, word egter ook ter sprake gebring, sonder 'n onhoudbare "Christologiese" interpretasie of die "indra" van Christus in die Ou Testamentiese teks in. In die preek moet die Ou Testamentiese teks steeds met die huidige gelowige se selfverstaan en die verstaan van hom- of haarself as Christen in verband gebring word. Volgens die huidige beleid van omdigting moet daar gewaak word teen 'n onhoudbare Christologiese interpretasie van die Ou Testamentiese teks. Dit is 'n aanvaarbare uitgangspunt, maar dié beginsel word so ver geneem dat dit selfs beteken dat die leefwêreld van die singende Christen, ook nie in ag geneem word nie. Daar word ook nie gevra na die moontlike teenstrydige betekenisse wat (onder andere vanweë die vreemde wêreldbeeld wat gereflekteer word, of onbekende metafore) in die sing van die lied aan die teks toegeken kan word nie.

Alle omdigting is interpretasie. Die vraag is dus waarom die interpretasie net tot op 'n sekere punt gevoer mag word, soos 'n prediker wat by die eksegese vassteek sonder om by die "boodskap" vir die huidige tyd uit te kom. In die omdigtingsproses kan dit ook gebeur dat die eksegese van die psalm uiteindelik omgedig word. In die praktyk gebeur dit inderdaad dat nie-tekstuele, maar eksegetiese materiaal soms verduidelikend of uitbreidend "ingedig" word, sodat die betekenis en bedoeling van 'n bepaalde frase of gedagte duideliker kan word. Dit gebeur ook veral waar daar reeds 'n melodie vir 'n bepaalde psalm bestaan en daar, nadat inhoudelik alles nágesê is, nog musiekmateriaal "oor" is. Vanweë al die vlakke waarop daar dus voortdurend interpretasie plaasvind, blyk dit dat ' $n$ reproduktiewe omdigting hermeneuties nooit werklik moontlik kan wees nie.

\section{DIE LITURGIESE FUNKSIE VAN DIE PSALMS - DIE PRO- BLEEM MET 150 PSALMS.}

Die vraag na die houdbaarheid daarvan om al 150 psalms om te dig vir liturgiese gebruik hang saam met die vraag na die houdbaarheid van 'n reproduktiewe omdigting. Die kultusmilieu waarin baie van die psalms oorspronklik ingebed is, verskil totaal van ons huidige liturgiese konteks waar dit gaan om die radikaal nuwe boodskap van Jesus Christus. Hoe kan 'n Christelike gemeente byvoorbeeld die reproduktiewe omdigting van wraakpsalms sing - hoe moet 'n wraakpsalm liturgies funksioneer? Ander het reeds op dié saak gewys (vgl Serfontein 1956; Loader 1979). Loader wys daarop dat die 
Bybelse psalms reflekteer hoe ou Israel die ingrype van God in hulle lewe ervaar het. Die kerklied van vandag moet egter reflekteer hoe Christene God se ingrype in hulle lewens vandag ervaar. "Die groot verskil lê in die era van die Psalms en die era waarin ons ons bevind" (Loader 1979:167, vgl ook Manning hierbo).

Daar is 'n grondige verskil tussen 'n gemeente wat 'n reproduktiewe omdigting sing wat nie hermeneuties ontsluit is nie, téénoor 'n preek wat hermeneuties ontsluit is en wat die geloofsperspektief en konteks van die Christelike gemeente in berekening bring. Elke gelowige kan byvoorbeeld steeds bid dat die vyand se optrede teen hom of haar beperk moet word, maar die Christen mag tog nie vra dat die vyand se kinders teen die rots verpletter moet word nie (Ps 137). Dit is onvermydelik dat 'n Christen as méns in sekere omstandighede emosies van wraak sal ervaar, in die Bybelteks van 'n vloekpsalm hierdie emosies verwoord sal vind, hom of haarself daarmee kan vereenselwig en sodoende dalk sterk deur so 'n psalm aangespreek kan voel. Dit is ook so dat 'n gemeente in die lees en hoor van sodanige psalm, kollektief tot Einfühlung met die betrokkenes sal kan kom. Dit word egter 'n heel ander saak as so 'n lied sonder die Christelike perspektief en interpretasie (bv as gebed om die wraksug te oorkom) kollektief deur 'n Christelike gemeente gesing word.

Strydom (1994:338) betoog ten gunste van die Psalter as geheel en verwys na 'n gesprek met prof Casper Honders, waarvolgens hy sou vertel dat die kerk in Nederland, met die ervaring van ontwrigting en vrees tydens die Tweede Wêreldoorlog, behoefte gehad het aan die sing van totaal ander psalms as onder normale omstandighede. Die behoefte is verstaanbaar - miskien juis in die huidige omstandighede in Suid-Afrika, waar families ly onder moord en misdaad en dit wil voorkom asof geregtigheid nie geskied nie. Maar die vraag bly of ' $n$ Christengemeente in enige omstandighede deur die sing van 'n lied kollektief die vyand mag vervloek of wraak sweer, hoe sterk die individuele of selfs die kollektiewe ervaring ook al is? In die gemeente kan 'n wraak- of vloekpsalm gelees word en vanuit 'n Christelike perspektief geïnterpreteer word. Serfontein (1956) sê in dié verband:

Die worsteling van Du Toit, en die groot Nederlandse berymers voor hom, met sulke Psalms dwing bewondering af, maar as die resultaat dan tog nog 
onsingbaar bly, kan die goeie reg vir die opname daarvan in 'n kerkboek moeilik geregverdig word. 'n Beryming word immers gemaak en opgeneem in die liedereboek om gesing te word: bestaan die noodsaak tog om een of ander rede dat dit liewer nie in die erediens aangehef moet word nie, kan dit o.i. beter in die prosavorm (sic) in die Bybel bly.

(Serfontein 1956:242)

Dit is egter nie net wrakpsalms waarvan die liturgiese funksie problematies is nie. Psalm 45 word oor die wêreld slegs in enkele liedboeke gevind - net in dié waar al 150 psalms opgeneem word. Waar liturgiese bruikbaarheid en funksionering egter 'n kriterium is, kom hierdie psalm nie voor nie. Die redes daarvoor is duidelik. Die psalm handel naamlik oor lofprysing aan die aardse koning tydens 'n bruilofsfees. Dit word algaande duidelik dat hier van ' $n$ harem sprake is. Die koning se skoonheid en skatte word besing, die koningin sit aan sy regterhand, terwyl die nuwe prinses hom as bruid tegemoet tree. Ten slotte word die koning vrugbaarheid toegewens en die wens uitgespreek dat hy seuns mag verwek. Die vraag is waar hierdie lied binne die Christelike liturgie tereg moet kom? Die opmerking is al gemaak dat dit 'n goeie huwelikslied sal wees(!)

In watter gevalle sou "veranderings" wel wettig wees ten spyte van die huidige rigiede uitgangspunte? Waarom mag Psalm 119 om pragmatiese redes verkort word, maar ander psalms moet in die volle, uitgesponne lengte verskyn? Wanneer daar gestel word dat die psalms soos hulle in die Bybel verskyn (vgl Van Wyk 1994:49) berym moet word, beteken dit wel dat elke beeld, metafoor en elke pleknaam getrou weergegee moet word, soos tans vereis word? Wat gebeur as eksegete nie eenstemmig is oor wat alles in die Bybelteks beteken nie? Waarvoor moet die digter kies? Wie bepaal watter interpretasiemoontlikhede wat in 'n Bybelteks ontsluit kan word, deur 'n digter omgedig moet word? Wie besluit uiteindelik dat 'n digter se interpretasie in 'n reproduktiewe omdigting (let op die teenspraak!) wel die regte interpretasie is wat die Bybelteks reproduktief weergee? Watter kriteria kom uiteindelik ter sprake wanneer 'n paar digters 'n teks verskillend interpreteer en 'n keuse gemaak moet word? Tans word volgens 'n 
beleid van konsensus gewerk. Waar ' $n$ ander groep bymekaar sou wees rondom dieselfde saak, sou die konsensus heel anders kon lyk.

In sekere liedboeke soos die Psalter Hymnal van die Christian Reformed Church in North America en Liedboek voor de Kerken waarin al 150 Psalms opgeneem is, is ook 'n rubriek met die naam "Bybelliedere". Daaronder ressorteer omdigtings van psalms in 'n meer vrye vorm én omdigtings van ander Bybelgedeeltes. Sodanige moontlikheid tot omdigting van verskeie Bybelgedeeltes, is vanselfsprekend, omdat soveel as moontlik uit die Bybel in 'n liedboek tereg behoort te kom. Dit beteken egter steeds dat elke omdigting (van watter gedeelte ook al) 'n interpretasie is, dus 'n hermeneutiese ontsluiting deur die teksdigter. Om met betrekking tot die psalms 'n onderskeid te maak tussen "psalms" waar daar so na as moontlik aan die oorspronklike gehou word en "psalms as Bybelliedere" wat 'n meer vrye interpretasie is, is hermeneuties, sowel as wat liturgiese gebruik betref, 'n onegte onderskeid. Dit is 'n vreemde teologiese dubbelslagtigheid: waarom geld hierdie uitgangspunt slegs vir die psalms en nie ook vir ander Bybelgedeeltes nie?

Meerdere interpretasies van 'n teks of 'n aspek van 'n teks is altyd moontlik. Daar is dus ook meer omdigtings van 'n teks moontlik, omdat elke omdigting op 'n bepaalde gedagtepatroon kan konsentreer, 'n ander perspektief kan uitlig of 'n ander interpretasie kan wees - dit bly steeds 'n psalm. Wanneer 'n omdigting werklik 'n kunswerk is waarin egte geloofservaring uitgedruk word en 'n Christengemeente teologies daarmee kan assosieer, behoort dit as 'n moontlike interpretasie aanvaar te word, sonder om dit tot 'n "reproduksie" te dwing - dus sonder om dit eenduidig te laat ooreenstem met die resultate van een bepaalde eksegese (wat dikwels pretendeer om die laaste woord te wees.) Met 'n reproduksie word uiteindelik aan meerduidigheid en literêre gehalte, maar veral outentieke aangespreek-wees ingeboet. Deans (1999:230) sê: "It is arguable that the practice of versifying large sections of Scripture - particularly from the Psalter helped to stifle theological development, to stunt spiritual growth, and to hamper the process of creative imagination for several centuries". 


\section{TEKSTE MOET SINGBARE EN SINVOLLE EENHEDE WEES}

Die huidige uitgangspunt van 'n reproduktiewe omdigting, het dikwels lang strofes en/of tekste met baie strofes tot gevolg. Dit beïnvloed die liturgiese funksionering negatief. Aangesien die uitgangspunt is dat elke psalm ten volle omgedig moet word, is die nuwe omdigtings oor die algemeen te lank om as singbare en sinvolle eenhede te funksioneer. Dit is dikwels ook baie moeilik om 'n sinvolle seleksie van strofes te maak. 'n Seleksie van strofes fragmenteer meestal 'n lied. Baie nuutomgedigte psalms het ook geen tematiese eenheid nie, omdat die psalm self geen tematiese eenheid vertoon nie. Lof, wraak, gebede en historiese gegewens staan dikwels naas mekaar in een lied. Ook dit beïnvloed die liturgiese funksionering negatief. Waar in die liturgie funksioneer 'n psalm met gemengde tematiek sinvol? Die huidige Psalmkommissie sien nie kans om op die hoofgedagtelyne te konsentreer en 'n lied of liedere wat tematies 'n eenheid vorm daar te stel nie (vgl Loader se voorstelle 1979:173) omdat dit die "teksgetrouheid" sal beïnvloed. Wat word egter van die beginsel van "getrouheid aan die Woord", wanneer liturge weens die lengte van die liedere tot 'n seleksie van strofes gedwing word?

Soveel moeite word tans met die geheel van die teks gedoen, maar hoe dit uiteindelik liturgies as lied moet funksioneer, word buite rekening gelaat. Daar word ure oor die "korrektheid" van die geheel van die liedteks geredeneer, maar onder die slagspreuk dat op 'n "liturgies verantwoorde wyse" 'n aantal strofes gekies moet word, word die keuse aan die liturg oorgelaat om die lied na willekeur te fragmenteer en strofes na willekeur saam te voeg of weg te laat. ' $n$ Kerklied, soos enige ander gedig, behoort ' $n$ eenheid te vorm en behoort as 'n eenheid te funksioneer - daaroor is himnoloë eenstemmig. 'n Gesaghebbende himnoloog, prof Dick Watson, tot onlangs hoof van die Department of English Studies aan Durham University, verwys na die belang daarvan dat 'n kerklied 'n sinvolle eenheid moet vorm - "a properly structured entity, not some collection of stanzas". Hy verwys na James Montgomery (1771-1854) se stellings in dié verband (Montgomery in Watson 1998:14 - my kursivering): "A hymn must have a beginning, middle, and end. There should be a manifest gradation in the thoughts, and their mutual dependence should be so perceptible that they could not be transposed without injuring the unity of the piece; every line carrying forward the connection, and every verse adding a well-proportioned limb to a symmetrical body" 


\section{DINAMIESE NUWE AFRIKAANS?}

Van die begin af is gesê dat die omdigting in nuwe Afrikaans moet wees (vgl Van Wyk 1994:49). Daar bestaan egter 'n vreemde diskrepansie tussen die "nuwe" Afrikaans wat tans in die omdigtings gebruik word en die "ou" leefwêreld wat reproduktief daarin weerspieël word. In baie van die nuwe omdigtings word ook 'n ouer taalregister gebruik. In die nuwe Psalm 38 kom die woorde roede, gramskap, tugtig, steeds voor. Die tweede strofe se aanvangsreël is ook in 'n ouer register: "Van u pyle dra my wonde, weens my sonde ..." Die woordorde is dikwels onnatuurlik: "Ek is stukkend, seer is in my elke plek" (str 2), of die segging het 'n vreemde betekenis vir bepaalde groepe: "Hulle soek my dooie liggaam - ek bly lydsaam ..." (str 5) (Psalm van T T Cloete - reeds deur Psalmkommissie goedgekeur.)

Eietydse, "nuwe" Afrikaans en goeie omdigtings, los nie die teologiese probleme op nie. 'n Nuwe omdigting van Psalm 133 is baie positief deur die eksegete ontvang: dit sê wat die Bybelteks sê. Die musici het daarop gewys hoe goed die woord en musiek by mekaar pas. Die liturgiese funksionering bly egter problematies. Die metafore en vergelykings is so vreemd dat die lied nie maklik as eietydse geloofsverwoording kan funksioneer nie. As dit daarom gaan dat dit goed is dat mense in vrede saamleef, moet dit met eietydse metafore weergegee word. Daar moet dan ook na mense verwys word en nie slegs na broers nie. Die gebrek aan inklusiewe taal is hier, soos deurgaans in die omdigtings, 'n ernstige probleem.

\footnotetext{
Hoe goed is dit as broers in vrede saamwoon soos salwingsolie van Aäron afstroom, oor hoof en baard tot by sy soom.

Dit is soos dou, die dou van Hermonsberg, wat daal op Șion, soos 'n sagte reèn waar broers só leef, gee God sy seën.
}

\section{MELODIEË BY NUWE OMDIGTINGS}

Die vraag word dikwels gestel of die melodieë by die nuwe omdigtings "singbaar" gaan wees. In beginsel is alle liedere "singbaar" - dit hang van die vermoëns en vlak van 
opleiding, maar veral ook van die mate van blootstelling aan 'n melodie af. Die musiekkommissie is bewus daarvan dat nuwe toonsettings nuut moet wees en nie "Geneefs" of "neo-Geneefs" moet klink nie, maar die probleem lê tans meestal by die "nuwe" tekste wat getoonset moet word. Ten einde alles uit die oorspronklike teks weer te gee, word die strofes en ook die versreëls soms so lank dat selfs 'n nuwe musiekkomposisie as toonsetting van die teks, reeds iets argaïes vertoon. Waar van die nuwe omdigtings en hulle musiek al bekend gemaak is, is die beskuldiging reeds herhaaldelik gemaak dat die melodieë kwasi-Geneefs klink. Die probleem lê egter by tekste met lang strofes en veral lang versreëls, wat hierdie gevoel veroorsaak. Lang versreëls en strofes skep dikwels by die hedendaagse gelowige ' $n$ gevoel van iets argaïes. Dit is die oorsaak van baie van die weerstand teen van die huidige psalms - 'n weerstand wat sonder twyfel ook by verskeie van die nuwe omdigting ondervind gaan word.

Verwysings na die melodieë is vir die doeleindes van dié artikel doelbewus buite die bespreking gelaat, om vanuit ' $n$ teologiese oogpunt ongeïnterpreteerde voorveronderstellings, 'n onkritiese omgang met tradisies, fundamentalistiese uitgangspunte en 'n positivistiese dwangbuis, bloot te lê. Daar is ook gewys op die minagting van die huidige gelowige (Christen) se ervaringswêreld waarbinne hierdie liedere moet neerslag vind ten einde 'n ware geloofslied te word, as faktore wat die huidige omdigting en die verwagte resepsie daarvan kan problematiseer. Die probleme rondom die musiek kan baie verminder word indien bogenoemde probleme rondom die tekste aangespreek word. Tans kry sogenaamde "onsingbare melodieë" dikwels die alleen-skuld vir alles wat nie vlot nie. Die "gewone" lidmaat het nie altyd die vermoë om te onderskei wat die invloed van die teks op die melodie is nie en lê probleme net voor die deur van die melodie. Ongelukkig speel predikante en teoloë dikwels self 'n negatiewe rol, omdat hulle ook nie oor die vermoë tot onderskeid beskik nie. Sodoende word negatiewe persepsies ten onregte rondom die musiek van liedere gevestig. 


\section{SAMEVATTING}

\subsection{Psalms is wêreldwyd nié die norm nie.}

Psalmsang is 'n intrinsiek ekumeniese simbool en toon wêreldwyd 'n oplewing, omdat gelowiges opnuut hulle geloof/kleingeloof/klag/lof in die psalmtekste verwoord vind. In liedboeke oor die wêreld, is al 150 psalms in berymde vorm egter skaars. Reformatoriese kerke oor die wêreld het oor die algemeen 'n seleksie van psalms in hul liedboeke. Die psalms word ook in baie verskillende vorms opgeneem: náás langer strofiese omdigtings, ook onberymde psalms, kortvorme, uitroepe, kanons en sogenaamde Singsprüche (vgl veral die nuutste liedboek van die Reformierte Kirche in Switzerland 1998.) Al hierdie vorme word egter steeds as psalms beskou. Die strofiese omdigtings in die liedboeke het ook ' $n$ beperkte aantal strofes, sodat elke lied as 'n eenheid gesing kan word.

\subsection{Verantwoorde hermeneutiese ontsluiting is noodsaaklik}

Hoe núut kan omgedigte tekste wat reproduktief 'n ou wêreldbeeld reflekteer, in die mond van hedendaagse gelowiges klink? Hoe kan 'n liedteks as eietydse geloofsverwoording dien, wanneer dit nie hermeneuties vir die hedendaagse gelowige ontsluit is nie? Watter liturgiese funksie het dit uiteindelik? Die spesifieke van die erediens lê in die "Moment der Darstellung, der Symbolisierung" (Cornehl 1974:461). Die lied as liturgiese geloofsuiting kom eers in die daadwerklike voltrekking tereg en kan slegs van daaruit omvattend verstaan word: gereproduseerde kunsvorms in liedboeke het weinig betekenis. Só lê die spesifieke moment van liturgiese sang nie in dít wat in liedboeke vasgelê is, of wat oor liturgiese musiek gesê word nie, maar in die konkrete sanghandeling. Indien die sing van psalms ons ems is en die psalms nie net as 'n soort gereproduseerde "kunsvorm" uit die Ou Testament in 'n liedboek geplaas moet word nie, moet oor al bogenoemde sake daadwerklik besin word, vóórdat 'n nuwe psalmomdigting in die finale vorm aan die Kerk voorgelê kan word.

You must be preserved from the antiquarian peril. Hymns are for Christians, not for poets nor for antiquarians. One persistent trouble is that, having shut the door against the poet, you find the antiquarian flying in at the window - 
the antiquarian who demands the original text whatever the cost in taste or style (which are small matters) or in the power to express real religious faith (which is a great matter). The business of a hymn is to strengthen the faith of today, and not to present a historical record of the faith the day before yesterday.

(Manning 1942:116-117)

\section{Literatuurverwysings}

Cornehl, P 1974. Gottesdienst, in Klostermann 1974:447-465.

Deans, G 1999. Hymnody and belonging. Part 1: The words of hymnody. Bulletin 220 (HSGBI), 230-238.

Evangelisch-reformierten Kirchen der deutschsprachigen Schweiz 1998. Gesangbuch.

Zürich: Theologischer Verlag.

Jauß, H R 1969. Literaturgeschichte als Provokation der Literaturwissenschaft. 2. Aufl. Konstanz.

Jauß, H R \& Godzich, W 1982. Aesthetic Experience and Literary Hermeneutics. Minneapolis: University of Minnesota Press.

Klostermann, F \& Zerfass, R 1974. Praktische Theologie heute. München: Kaiser.

Kloppers, E C 1992. Die Lutherse kerkkantate van die Barok as musikale prediking. Ongepubliseerde BMusHons-skripsie, Universiteit van Pretoria.

- 1994a. Liturgiese koorsang as wyse van kerklike verkondiging - 'n Prinsipiële besinning vanuit hermeneuties-homiletiese perspektief. HTS 50(3), 583-609.

- 1994b. Riglyne vir sinvolle vernuwing van liturgiese musiek. Ongepubliseerde Referaat: Predikantevergadering Ned Herv Kerk 1994.

- 1997. Liturgiese musiek as kommunikatiewe handeling in 'n postmoderne era. Ongepubliseerde DTh-proefskrif, UNISA.

Loader, J A (red) 1979. ' $n$ Nuwe lied vir die Here. Pretoria: HAUM.

Loader, J A 1979. Waarom sing ons in die kerk?, in Loader, J A 1979:160-177.

Manning, B L 1942. The Hymns of Wesley and Watts. London: Epworth.

Ricoeur, P 1987. Erzählung, Metapher und Interpretationstheorie. ZThK 84, 232-253. 
Serfontein, W J B 1956. Die Psalm as kerklied: Teologiese agtergronde van die Afrikaanse Psalmberyming. Nijkerk: Callenbach.

Strydom, W M L 1994. "Sing nuwe sange, nuutgebore": Liturgie en lied. Bloemfontein: UOVS.

Van Wyk, D J C 1994. Die kerklied: prinsipiële, historiese en praktiese oorwegings. Ongepubliseerde Referaat: Predikantevergadering Ned Herv Kerk 1994.

Watson, J R 1998. Alphas and Omegas of Hymn Writing. IAH Bulletin 26, 5-17. 